\title{
Da opressão à independência. A filosofia do amor em O Segundo Sexo'
}

\author{
From Oppression to Independence: Beauvoir's \\ Philosophy of Love in The Second Sex
}

\section{Manon Garciaa}

\section{Traduzido por Ana Flávia P. L. Bádue ${ }^{b} \odot$}

\begin{abstract}
Resumo Neste ensaio, Manon Garcia analisa o lugar da filosofia do amor no argumento geral de Simone de Beauvoir sobre a opressão feminina e defende que, embora o amor pareça desempenhar um papel secundário n'O Segundo Sexo, ele tem papel fundamental para responder à pergunta “o que é uma mulher?”. Garcia defende que o amor é central para a análise que Beauvoir faz da opressão das mulheres, na medida em que constitui o fundamento ideológico da objetificação das mulheres e estrutura as ambiguidades das experiências vividas da opressão. Ao mesmo tempo, Garcia aponta que, para Beauvoir, o amor pode ser um recurso para a emancipação das mulheres no nível individual.
\end{abstract}

\begin{abstract}
In this essay, Manon Garcia analyzes the role played by the philosophy of love in Simone de Beauvoir's approach on the feminine oppression. Garcia claims that, while love seems to be a minor issue in The Second Sex, it is actually fundamental to answer the question "What is a woman". Garcia posits that love is central to Beauvoir's analysis on women's oppression to the extent that it constitutes the ideological foundation of the objectification of women and it structures the ambiguities of the lived experiences of oppression. At the same time, Garcia suggests that, to Beauvoir, love can be a resource to female emancipation on the individual level.
\end{abstract}

Mais do que por seus escritos ou seus posicionamentos políticos, Simone de Beauvoir tornou-se célebre, sobretudo na França, por ser parte deum dos casais mais escandalosos do século XX, junto com Sartre. Inúmeros escritores e filósofos alcançaram conquistas diversas publicamente, mas Sartre e Beauvoir foram excepcionais. Tornaram-se conhecidos tanto como casal quanto individualmente,

\footnotetext{
1 Referência para o artigo original: GARCIA, Manon (2020). "De l'oppression à l'indépendance. La philosophie de l'amour dans Le Deuxième Sexe”.Philosophie, $\mathrm{n}^{\circ} 144$.

a Professora doutora no Departamento de Filosofia da Yale University.

b Doutoranda do Programa de Antropologia no The Graduate Center, City University of New York.
} 
como uma unidade de "amor necessária", em contraste com os diversos "amores contingentes" que tiveram durante suas vidas. Desde a publicação de $A$ Convidada, em 1943, e de Os Mandarins, dez anos depois, e ainda mais após a publicação das cartas de Beauvoir a Sartre (Beauvoir, 1983), Algren (Beauvoir, 1997) e Bost (Beauvoir e Bost, 2004), o casal feito de liberdade e libertinagem vem seduzindo biógrafos e comentadores. Nesse contexto, Simone de Beauvoir aparece de duas maneiras contraditórias: a partir das memórias de sua antiga aluna e amante Bianca Lamblin (1993) e do conflito com Benny Levy e outros à época do fim da vida de Sartre, Beauvoir é retratada como mulher frustrada, austera e ciumenta, inteiramente submissa a Sartre, a ponto de suas aventuras sensuais com jovens alunas aparecerem somente como forma de "recrutá-las" para Sartre, pois estaria preocupada em manter controle sobre ele a qualquer custo ${ }^{2}$. Por outro lado, as cartas a Algren, a Lanzmann ${ }^{3}$ e a Bost desvelam uma mulher amorosa, sensual, divertida, que fazia do amor uma das grandes experiências da sua existência. Se os diversos materiais inéditos publicados ao longo dos anos por sua filha adotiva Sylvie Le Bom de Beauvoir mostram que o segundo retrato é de longe o mais fiel $^{4}$, falta a essas duas imagens o que há de mais importante no relacionamento de Beauvoir com o amor: a filosofia do amor que ela desenvolve em seus textos teóricos e ilustra nos seus romances e relatos ${ }^{5}$.

A filosofia do amor de Beauvoir tornou-se objeto de alguns - poucos - estudos ${ }^{6}$, mas estes se concentram principalmente em uma descrição das formas de amor que aparecem em $O$ Segundo Sexo, sem questionar o lugar da filosofia do amor no argumento geral de Beauvoir sobre a opressão feminina. Embora a filosofia do amor pareça desempenhar um papel secundário n'O Segundo Sexo e não ser mais do que um subproduto da resposta à questão “o que é uma mulher?”, eu pretendo mostrar aqui que, para Beauvoir, a transformação do amor heterossexual é o principal meio de conversão da opressão em emancipação no nível individual.

2 Veja-se, por exemplo, as críticas amargas feitas àquele que pode ser considerado o último tomo de suas memórias, La Cérémonie des adieux, publicado em 1981, no qual Beauvoir descreveu as últimas semanas da vida de Sartre.

3 Depois de um conflito entre Claude Lanzmann e Sylvie Le Bom de Beauvoir, filha adotiva e herdeira testamentária de Beauvoir, essas cartas não foram publicadas e Claude Lanzmann as vendeu em 2018 para a biblioteca da Universidade de Yale, nos Estados Unidos, onde podem ser consultadas.

4 O único trabalho biográfico que faz uma análise completa dessas novas fontes e que responde às questões sobre a distância entre os relatos das memórias e a realidade da vida de Simone de Beauvoir é a excelente biografia de Kate Kirkpatrick (2019).

5 A publicação de Cahiers de jeunesse de Beauvoir em 2008 mostra que a questão filosófica sobre o amor já estava no centro dos escritos da jovem Simone de Beauvoir (2008).

6 Os dois estudos mais importantes sobre o assunto são: Cleary (2017) e Pettersen (2017). Há também Lacaze (2015); Mcmullin (2011); Klaw (1997); Heinämaa (2006). 
Como demonstraram os trabalhos de Skye Cleary (2017) e de Tove Pettersen (2017), Beauvoir propõe uma análise de diferentes formas de amor: o amor romântico heterossexual, o amor lésbico, o amor maternal e a amizade. No entanto, afirmarei aqui que o amor romântico heterossexual tem um estatuto específico, com o qual todas as outras formas de amor são comparadas e, principalmente cuja evolução se encontra, segundo Beauvoir, como via de emancipação.

Pode-se pensar que o amor tem um lugar secundário n'O Segundo Sexo uma vez quea aposta aparente do livro é justamente definir a mulher ${ }^{7}$. Mas é através do estudo do amor romântico heterossexual que Beauvoir vai mostrar, pelo contrário, como os homens podem fixar a figura do Outro, como as mulheres podem ser tentadas a se comprazerem dessa figura e como os papeis fixos do Sujeito e do Outro podem se transformar ao dar lugar a um reconhecimento mútuo e dialético através do qual homens e mulheres poderão se encontrar como iguais em um Mitsein $^{8}$ fraternal e também carnal.

\section{O AMOR-OPRESSÃO OU A MULHER COMO REFLEXO AOS OLHOS DO HOMEM}

A primeira e mais evidente forma que o amor aparece em O Segundo Sexo é como fonte de justificativas paradoxais da opressão das mulheres. Enquanto poder-se-ia crer que as mulheres são oprimidas em razão da diferença entre os sexos, Beauvoir, sem negar a existência dessa diferença, mostra que seu valor vem da maneira pela qual o mito do eterno feminino como alteridade eterna e absoluta foi construído pelos homens. Podemos ler o primeiro volume d'O Segundo Sexo como o desenvolvimento da tese de que a especificidade da dominação masculina - e sua força - repousa no fato de ser uma dominação fundada sobre o amor e justificada pelo amor.

7 Quando Beauvoir fala da mulher ou das mulheres, ela não parte da hipótese de uma natura imutável ou de uma experiência universalmente partilhada pelas mulheres. A segunda parte do livro é dedicada a uma fenomenologia da experiência vivida das mulheres em diferentes etapas da vida, e em função de diferentes figuras. As generalizações a levam a falar da menina, da jovem mulher, da mãe. O que está em jogo, portanto, é jogar luz não sobre uma natureza feminina ou uma experiência universal de todas as mulheres, mas sobre uma situação sobretudo econômica e social que se manifesta como um "destino tradicional" que vem do exterior e é traçado para as mulheres: "Quando emprego as palavras "mulher" ou "feminino" não me refiro evidentemente a nenhum arquétipo, a nenhuma essência imutável; após a maior parte de minhas afirmações cabe subentender: 'no estado atual da educação e dos costumes'. Não se trata aqui de enunciar verdades eternas, mas de descrever o fundo comum sobre o qual se desenvolve toda a existência feminina singular" (Beauvoir, 1986b, p. 2)

8 [N.T.] O termo alemão mitsein é traduzido para o português como ser-com. 
Desde a primeira página da Introdução, Beauvoir levanta a questão que será fundamental em O Segundo Sexo: “o que é uma mulher?” (Beauvoir, 1986a, p. 9). Ela começa por rejeitar, em um só movimento, as duas respostas clássicas a essa questão: a resposta essencialista - as mulheres são fêmeas humanas cuja natureza lhes faz essencialmente diferente dos homens - e a reposta nominalista - nada além do nome que se carrega diferencia homens e mulheres -enquanto reivindica a existência de uma diferença evidente entre os sexos ${ }^{9}$. Mesmo que ela não explique exatamente como essa diferença funciona - essa é a tarefa de toda a obra - Beauvoir propõe a seguinte ideia: uma mulher está intrinsecamente ligada ao amor. A mulher trotskista, por exemplo, pode fingir que não é uma mulher por ser militante, mas ela é uma mulher porque age movida pelo amor, é o amor que guia suas ações e seu ativismo político. Além disso, a especificidade da opressão da mulher, o fato de que ela seja o Outro e não reclame o reconhecimento mútuo, está ligada ao amor: ela é o Outro porque é ela que o homem ama. Uma das ideias mais difundidas sobre a diferença sexual, ainda mais do que a visão biológica da mulher, é a da mulher como objeto de amor do homem, a qual funda o mito do Eterno feminino criticado por Beauvoir.

O desenvolvimento dessa tese contra intuitiva segundo a qual a concepção da diferença sexual, e eventualmente da justificação da dominação dos homens sobre as mulheres, está ligada a uma concepção de amor (mais do que à biologia)que ocupa grande parte do primeiro volume d'O Segundo Sexo. O primeiro capítulo, que Beauvoir consagra aos dados biológicos, introduz a obra com uma revisão das diferentes explicações filosóficas sobre a diferença sexual e se apoia no mito de Phèdre para iluminar o papel do desejo masculino na diferença social entre os sexos. Beauvoir se opõe a uma leitura clássica desse mito, visando ilustrar as origens da diferença sexual: normalmente o mito platônico dos corpos divididos se aplica à diferença sexual, enquanto que "é só o amor que essa história se propõe explicar" (Beauvoir, 1986a, p. 40). Essa tendência em misturar o problema de saber o que é o amor ao da origem da diferença sexual é explicado pela posição masculina:

É exercendo a atividade sexual que os homens definem os sexos e suas relações, como criam o sentido e o valor de todas as funções que cumprem: mas ela não

9 "E, em verdade, basta passear de olhos abertos para comprovar que a humanidade se reparte em duas categorias de indivíduos, cujas roupas, rostos, corpos, sorrisos, atitudes, interesses, ocupações são manifestamente diferentes: talvez essas diferenças sejam superficiais, talvez se destinem a desaparecer. O certo é que por enquanto elas existem com uma evidência total". (Beauvoir, 1986a, p. 11). 
está necessariamente implicada na natureza do ser humano. (Beauvoir, 1986a, p. 41)

Essa passagem ilumina uma confusão entre biologia e eros: segundo Beauvoir, não é a biologia, mas o sentido que os humanos lhe atribuem, nesse caso o sentido que o desejo masculino pode lhe atribuir, que explica o valor dado às diferenças que, do contrário, não seriam nada além de variações anatômicas. Logo, o eros masculino tematiza a diferença sexual e o ser de uma mulher é menos resultante de dados biológicos do que da maneira como os homens vê em nas mulheres a possibilidade de uma realização de seu desejo. Esse papel do olhar masculino sobre a constituição da feminilidade é ainda mais evidente na construção da figura de Eva: Eva, a mulher por excelência, não é, a princípio, um ser humano livre. Ela é feita aos moldes de Adão, é destinada a Adão, nasce dele e para ele. $\mathrm{O}$ modo como a diferença dos sexos é pensada na sociedade não se ancora em uma análise biológica, mas em uma concepção do casal heterossexual como unidade primeira da organização social e como uma unidade na qual a mulher se define por complementaridade em relação ao homem.

O amor, mais do que as diferenças sexuais no sentido biológico, está, portanto, no fundamento da construção da feminilidade pelos homens e, por consequência, no fundamento da opressão das mulheres pelos homens. Mais precisamente, Beauvoir se apropria das análises hegelianas do reconhecimento ${ }^{10}$ para mostrar que a opressão das mulheres pelos homens está fundada no, e é justificada pelo, amor, e que essa opressão pelo amor vem de uma abordagem inautêntica do reconhecimento mútuo. Com efeito, a apropriação de Hegel leva-a a concluir que o amor está no coração da opressão das mulheres porque é em seu nome que os homens negam às mulheres o reconhecimento mútuo e as fixam em uma alteridade da qual elas não podem escapar. Beauvoir faz da inautenticidade no contexto da tragédia da consciência infeliz o coração da opressão das mulheres.

A particularidade da opressão das mulheres pelos homens, segundo Beauvoir, vem do fato que a mulher não somente é construída como uma outra, mas como uma Outra, ou seja, como um ser cuja alteridade é irreversível, inelutável e absoluta. Para mostrar esse ponto, ela parte de uma concepção de alteridade que provém de sua leitura do conflito pelo reconhecimento de Hegel, leitura fortemente influenciada pela interpretação de Alexandre Kojève, mesmo que ela rejeite a

10 Mesmo que minha interpretação sobre o modo como Beauvoir combina essas duas apropriações divirja da de Nancy Bauer (2001a), minha análise é fortemente ancorada em seu artigo "Beingwith as Being-against: Heidegger meets Hegel in The Second Sex". 
identificação das relações de poder homens-mulheres à dialética do senhor e do escravo $^{11}$. A originalidade de sua reapropriação de Hegel é que Beauvoir não vê na alteridade um obstáculo insuperável para um acordo entre humanos. Na realidade, essa concepção agonística de alteridade é contrabalanceada pelo lugar que ela concebe ao conceito heideggeriano de Mitsein ${ }^{12}$. Segundo Heidegger, em Ser e Tempo ${ }^{13}$, uma das consequências cruciais da interdependência entre o Dasein e o mundo é que o indivíduo não está isolado, pois é socializado com outros; o Dasein é sempre com os outros. Diferente da concepção de alteridade proposta por Hegel dentro da perspectiva do conflito por reconhecimento, e da retomada de Sartre a essa ideia de que a relação com o outro só pode se fazer de um modo agonístico, Heidegger concebe a relação com os outros primeiramente como uma relação harmoniosa. Assim como na vida quotidiana, eu não me dou conta das coisas que me cercam e que participam da totalidade que é meu mundo, os outros também não são obstáculos nessa vida cotidiana. Na maior parte do tempo, minha relação com os outros é uma relação neutra - eu passo a seu lado e sou indiferente - ou positiva, uma vez que eu busco ajudar o outro, por exemplo. A relação com o

11 A literatura secundária sobre a apropriação de Hegel por Beauvoir, em particular os trabalhos de Nancy Bauer e de Eva Lundgren-Gothlin, tende a considerar que Beauvoir só utiliza Hegel por meio da leitura que Kojèvefez em seu curso sobre o Fenomenologia do Espírito em Paris nos anos 1930 (cf. Bauer (2001b) e Lundgren-Gothlin (1991) a partir da página 25. A participação de Merleau-Ponty e de Queneau nesse curso, ambos próximos a Beauvoir, e a importância da leitura kojèviana para a recepção de Hegel na França nos anos 1930 fazem com que seja quase certo que Beauvoir conhecia essa interpretação. Mas se a influência da leitura kojèviana é evidente em Beauvoir, sobretudo nessa passagem, é necessário enfatizar que Beauvoir é profunda conhecedora do texto hegeliano propriamente dito. O diário de 1940, transcrito em A Força da Idade, mostra que ela se dedicava cotidianamente à leitura do Fenomenologia do Espírito. Ela escreveu, por exemplo: "6 de julho de 1940. Fui à Biblioteca Nacional. Pedi um cartão e comecei a ler Hegel, A fenomenologia do espírito; por enquanto, não compreendo quase nada. Resolvi estudar Hegel todos os dias, de duas às cinco horas, é o que se pode encontrar de mais calmante" (Beauvoir, 1960). Portanto, ela não tem apenas um conhecimento de segunda mão, mediado pela leitura de Kojève. Ao contrário, a razão pela qual ela encontra calma ao ler Hegel no terrível contexto do início da Segunda Guerra mundial - o caráter metafísico, sistemático e abstrato da filosofia hegeliana - é também a razão de se distanciar, à medida em que ela mergulha e entende cada vez mais. Ela critica o sistema hegeliano por sua abstração, enquanto a filosofia heideggeriana, em sua insistência na concretude da experiência individual, permite que ela pense sobre sua própria situação (Beauvoir, 1960, p. 537-8). Nesse sentido, a utilização antropológica de Hegel não é simplesmente uma utilização das teses kojèvianas, mas resulta da sua convicção sobre a necessidade de pensar o indivíduo em suas determinidades concretas.

12 Cf. Bauer, 2001a.

13 A nosso ver, o modo como Beauvoir se apropria da filosofia de Heidegger foi pouco estudado. As duas análises importantes se encontram em Eva Lundgren-Gothlin e Nancy Bauer. Os poucos estudos a esse respeito atentam para a extrema dificuldade do texto heideggeriano e também para um problema mais profundo de tradução. De um lado, a língua francesa não se presta bem para traduzir o texto heideggeriano. A literatura francesa ou renunciou pura e simplesmente essa leitura, ou pensou os conceitos heideggerianos dentro de traduções já conhecidas, como a de Martineau. Mas Beauvoir usa os conceitos heideggerianos com uma tradução diferente. Como Sartre, ela fala de "realidade humana" para se referir ao que chamamos aqui, sem traduzir, de Dasein. Mas ela também fala de "desvelar" quando Martineau fala de "descobrir" (ver por exemplo o parágrafo 44 da tradução francesa de Ser e Tempo). 
outro não é, portanto, um conflito entre indivíduos, ela sequer é realmente uma relação. Ela consiste em habitar o mundo juntamente. De um lado, não há uma conflitualidade primordial entre os indivíduos que deve ser superada e, de outro lado, a independência e a autonomia estão mais distantes do ser quotidiano do Dasein do que a empatia.

A ideia de a relação com os outros ser primordial e geralmente harmoniosa ou neutra é importante para compreender a posição beauvoiriana sobre a diferença sexual: a diferença sexual não é compreendida como forma de conflito - a dominação dos homens sobre as mulheres, por exemplo - ela pertence às evidências impensadas. Vivemos em um mundo no qual certos indivíduos são homens, outros mulheres e essa divisão não se apresenta ao pensamento como sujeito de reflexão. É apenas quando essa divisão coloca um problema - por exemplo, quando cria desigualdades injustas ou exclui certas pessoas - que ela constituiu um objeto de reflexão. Como aponta Nancy Bauer, ao utilizar as teorias hegelianas de alteridade ao mesmo tempo que o conceito heideggeriano de Mitsein, Beauvoir dá um novo sentido à análise da alteridade: trata-se, para ela, de compreender como essa alteridade absoluta da mulher é construída contra um ser-com harmonioso. A alteridade não é primordial, portanto a feminilidade como alteridade absoluta não é natural nem imutável, e sim produto de uma relação de poder que deve ser elucidada.

$\mathrm{O}$ argumento central de Beauvoir sobre a maneira como as mulheres são oprimidas pelos homens parte da ideia de que o mito do Eterno feminino, que é um mito sobre a mulher como objeto do amor, permite aos homens acessarem sua humanidade sem incorrerem no risco do reconhecimento mútuo. Como ela explica no início da parte consagrada aos "Mitos" no primeiro volume, o encontro de outros seres constitui, para o sujeito, ora uma forma de ver sua liberdade confirmada, ora um risco de conflito, pois cada consciência "tenta realizar-se reduzindo a outra à escravidão" (Beauvoir, 1986a, p. 240). A única maneira de reduzir o que Beauvoir, seguindo Sartre, chama de tragédia da consciência infeliz e de criação das categorias de senhor e escravo é a amizade. A amizade, que age quando duas consciências se reconhecem mutualmente como liberdades, é a única saída, mas ela requer uma autenticidade e uma generosidade que são, às vezes, perigosas e difíceis de alcançar:

Mas a amizade e a generosidade que realizam concretamente esse reconhecimento das liberdades não são virtudes fáceis; são seguramente a mais alta realização do homem, e desse modo é que ele se encontra em sua verdade: mas 
essa verdade é a de uma luta incessantemente esboçada e abolida. Ela exige que o homem se supere a cada instante. (...) Mas ele não aprecia a dificuldade; teme o perigo. Contraditoriamente, aspira à vida e ao repouso, à existência e ao ser; sabe muito bem que a 'inquietação do espírito' é o preço que tem de pagar pelo seu desenvolvimento, que sua distância em relação ao objeto é o que lhe custa sua presença em si: mas ele sonha com a quietude na inquietude e com uma plenitude opaca que a consciência habitaria, contudo. Esse sonho encarnado é precisamente a mulher; ela é o intermédio desejado entre a natureza exterior ao homem e o semelhante que lhe é por demais idêntico. Ela não lhe opõe nem o silêncio inimigo da natureza, nem a dura exigência de um reconhecimento recíproco; por um privilégio único, ela é uma consciência e no entretanto parece possível possuí-la em sua carne. Graças a ela, há um meio de escapar à implacável dialética do senhor e do escravo, que tem sua base na reciprocidade das liberdades. (Beauvoir, 1986a, p. 240-1)

A construção da mulher como Outro aparece então como a melhor maneira de escapar das dificuldades e perigos do reconhecimento mútuo ao obter o reconhecimento de sua própria liberdade. Os homens têm o poder de construir as mulheres como um tipo de ser suficientemente semelhante a eles por ter a capacidade de reconhecer suas liberdades, ao mesmo tempo suficientemente diferente por não ter a pretensão de ter um reconhecimento mútuo. A mulher é, portanto, concebida como um intermediário ideal entre o homem e o animal, que permite ao homem escapar da existência animal, cuja liberdade não é reconhecida por outrem, sem ter que fazer o esforço constante de sabedoria e generosidade que o reconhecimento mútuo requer.

A razão pela qual a figura da mulher como intermediário é importante para compreender a filosofia beauvoiriana do amor está no fato que a mulher é feita de intermediária enquanto é feita de objeto de amor. Como Beauvoir assevera na longa seção consagrada aos Mitos, o pensamento mítico transforma as mulheres singulares em instanciações do mito do Eterno Feminino, ou do mito de uma natureza única e fixa da Mulher, cuja função e destino são de ser possuída pelo homem. Nesse mito, a mulher é mãe, puta, virgem, mas em todo caso é indubitável e absolutamente distinta do homem, e fixada em sua alteridade e sua imanência absolutas, a ponto que nada pode ser dito sobre ela:

De uma camponesa pode-se dizer que se trata de uma boa ou má trabalhadora, de uma atriz que tem ou não talento; mas se se considera uma mulher em sua 
presença imanente, nada se pode dizer absolutamente, ela está aquém de qualquer qualificação. Ora, nas relações amorosas ou conjugais, em todas as relações em que a mulher é a vassala, o outro, é em sua imanência que é apreendida. É impressionante o fato de a companheira, a colega, a associada não terem mistério; em compensação, se o vassalo é masculino, se diante de um homem ou de uma mulher mais velhos do que ele, mais ricos, um rapaz se apresenta como o objeto inessencial, envolve-se ele também de mistério. (Beauvoir, 1986a, p. 401)

Não somente o amor fixa a mulher como uma alteridade que a exclui do mundo dos humanos concretos, mas funciona como um véu que mascara as dimensões materiais da opressão feminina. Um dos mecanismos fundamentais da opressão das mulheres e sua perpetuação é fazê-la passar por um problema individual e não uma questão estrutural e social. Na ideia do mistério feminino está escondido o fato de que a passividade e o mistério das mulheres são a consequência direta da organização patriarcal da sociedade e do direito. Por exemplo, Beauvoir mostra, no último capítulo da seção sobre os Mitos, que "Detendo o homem neste mundo uma situação privilegiada, ele é que pode manifestar ativamente seu amor; muitas vezes sustenta a mulher ou a ajuda. Desposando-a, dá-lhe uma posição social; dá-lhe presentes; sua independência econômica e social permite-lhe iniciativas e invenções" (Beauvoir, 1986a, p. 401). Por trabalharem fora de casa, serem herdeiros, terem salário, os homens podem agir, tomar iniciativas, enquanto a mulher que fica em casa ou a jovem que recebe seu pretendente estão em uma posição de passividade criada por uma organização social e legal do mundo no qual elas vivem. A passividade das mulheres é tida como um traço da natureza feminina e como uma escolha ou desejo das mulheres, mas na verdade ela é resultado da opressão estrutural das mulheres.

Assim, é em nome do amor que as mulheres são transformadas em um Outro mítico e misterioso, sobre o qual ninguém pode dizer nada e cuja alteridade parece a-histórica e essencial. A alteridade da mulher faz dela tanto um objeto de paixão quanto de rejeição, um outro adorado mas transformado por essa adoração em algo essencialmente diferente e inacessível. Esse papel do amor confere à opressão das mulheres um caráter original, paradoxal e particularmente perigoso. $\mathrm{Na}$ verdade, por um lado o amor dá lugar a uma diferença entre os sexos que funda uma opressão das mulheres pelos homens, mas por outro, ele cria essa situação original onde os opressores amam os oprimidos e os oprimidos amam os opressores. Para o homem, a mulher não é (apenas) um objeto de consumo ou algo para ser destruído, mas é um objeto para ser amado. Para a mulher, esse amor, 
indissociável da objetificação que cria, faz a opressão ser suportável e até mesmo justificável. Em ambos os casos, o papel do amor na opressão das mulheres faz com que essa opressão seja difícil de identificar, e ainda mais difícil de escapar: é difícil ver no amor uma fonte de opressão, ao passo que os prazeres e doçuras do amor fazem dele uma opressão sedutora.

\section{O AMOR-ABDICAÇÃO OU A EXPERIÊNCIA FEMININA DO AMOR COMO SUBMISSÃO}

Enquanto o primeiro volume d'O Segundo Sexo é consagrado a responder à questão "o que é uma mulher" do ponto de vista dos homens, ou do ponto de vista daqueles que tem o poder de fabricar essa definição, o segundo volume se debruça sobre a experiência vivida das mulheres, sobre a maneira como essa definição exterior da feminilidade apresentada no primeiro volume constrói o destino das mulheres, e sobre a maneira como as mulheres vivem esse destino. Em especial, Beauvoir propõe uma análise fenomenológica da maneira como as mulheres vivem a alteridade absoluta à qual são destinadas, e mostra que a experiência vivida das mulheres é acima de tudo a experiência de fazer de si mesma um objeto de amor.

Beauvoir propõe uma análise sobre como o amor e o erotismo são vividos pelas mulheres como forma de uma deliciosa submissão. Tanto na primeira parte, dedicada à formação das mulheres, quanto no capítulo sobre "A apaixonada", Beauvoir mostra que para as mulheres, e tão somente por elas, o amor toma a forma de abdicação. O ponto de partida dessa fenomenologia do amor é o seguinte: "A palavra "amor" não tem em absoluto o mesmo sentido para um e outro sexo. E é isso uma fonte dos graves mal-entendidos que os separam" (Beauvoir, 1986b, p. 539). Os homens têm uma relação de conquista com o amor, o qual não define sua existência ${ }^{14}$, de modo que, mesmo para os amantes mais apaixonados, as dores não duram muito e sua identidade não é posta em questão. $O$ amor constitui um tipo de complemento à vida dos homens, para quem o essencial se encontra fora de casa e em suas conquistas públicas, através das quais eles se assumem como seres livres no mundo. Para as mulheres, entretanto, o amor aparece como uma

14 "Em certos momentos de sua existência, alguns homens puderam ser amantes apaixonados, mas nenhum há que se possa definir como 'um grande apaixonado'; nunca abdicam totalmente, mesmo em seus mais violentos transportes; ainda que caiam de joelhos diante de sua amante, $o$ que desejam afinal é possuí-la, anexá-la; permanecem no cerne de sua vida como sujeitos soberanos; a mulher amada não passa de um alor entre outros; querem integrá-la em sua existência, e não afundar nela uma existência inteira. Para a mulher, ao contrário, o amor é uma renúncia total em proveito de um senhor" (Beauvoir, 1986b, p. 539-40). 
renúncia de si: o amor feminino normalmente consiste em "perder-se de corpo e alma em quem lhe designam como o absoluto, o essencial” (Beauvoir, 1986b, p. 540).

A peculiaridade da experiência vivida das mulheres, que faz com que essa experiência seja de opressão, consiste no amor-abdicação, que é apresentado primeiro às jovens e depois às adultas como a conquista de sua existência e, ao mesmo tempo, sua renúncia. Além de descrever o destino da mulher apaixonada, o capítulo sobre a mulher apaixonada tem valor crucial na análise beauvoiriana da opressão feminina pois ele contém os traços mais importantes de sua explicação sobre a submissão. O capítulo propõe uma fenomenologia da submissão feminina e mostra ora suas ambiguidades - a submissão não é simplesmente uma passividade e pode até constituir uma forma de poder -, ora sua inautenticidade.

O amor, para as mulheres, é uma forma particularmente profunda de submissão: a apaixonada busca constantemente se dissolver no homem que ama e perder sua identidade. Ao transformar esse homem em uma espécie de deus, ela tem prazer em servi-lo e ganha um sentido de si própria quando renuncia a si mesma. Beauvoir se apoia nos escritos de Juliette Drouet, Colette, Mme d'Agoult, Violette Leduc e de tantas outras mulheres, assim como nas análises de Hélène Deutsch e em suas próprias observações para fazer aparecer esse amor-submissão cujo desejo é "ser tudo para ele" (Beauvoir, 1986b, p. 556). Primeiramente, o amor e a submissão parecem funcionar juntos para definir aquilo que é profundamente o destino das mulheres. A jovem aprende que sua felicidade depende do fato de ser amada e que para ser amada ela terá que ser a presa de seu amante ${ }^{15}$. A formação da mulher passa pela tomada de consciência de que seu valor vem do exterior, do olhar do homem, e do amor que esse olhar poderá lhe dar. Ela deve ser escolhida, amada. Para sê-lo, ela deve renunciar a si mesma.

Mas a análise do amor revela, ao contrário da ideia comumente difundida de que submissão é pura passividade, que a mulher tem um papel ativo em sua submissão, ora tirando dela um prazer, ora extraindo dali uma forma de poder. Ela escreve: "Fazer-se objeto, fazer-se passiva não é a mesma coisa do que ser um objeto passivo: uma mulher amorosa não é nem uma dorminhoca nem uma morta; há nela um impulso que sem cessar se abate e se renova; é o impulso abatido que cria o encantamento em que o desejo se perpetua" (Beauvoir, 1986b, p. 155). A ambiguidade da submissão pode ser expressa como um erro da crença no destino submisso da mulher como simplesmente imposto pelo exterior. Pelo contrário,

15 "Ela aprende que para ser feliz é preciso ser amada; para ser amada é preciso aguardar o amor" (Beauvoir, 1986b, p. 43). 
como bem revela a figura da mulher apaixonada, a mulher age por conta própria para se conformar às normas sociais estudadas no primeiro volume e estabelecidas pela dominação masculina. Como demonstra Beauvoir ao comparar os arrepios do amor e os da confissão, e ao levantar as "delícias passivas" (Beauvoir, 1986b, p. 43) da submissão, a resignação da devota e da amante é fonte de um problemático entrelaçamento entre prazer e sofrimento. A submissão está longe de ser passiva. Essa ambiguidade da abdicação atinge seu paroxismo na discussão sobre o poder do masoquismo:

quer se trate de Deus, quer de um homem, a menina aprende que, aceitando as mais profundas renúncias, se tornará todo-poderosa; ela se compraz em um masoquismo que lhe promete supremas conquistas. (Beauvoir, 1986b. p. 44)

A submissão pode se converter em poder e dominação. Ao jogar luz sobre a ambiguidade da abdicação, Beauvoir desvela seus impasses e mentiras. A apaixonada submissa não é - ou pelo menos não apenas - uma vítima do homem que ama. Primeiramente, não é o homem individual, nem a natureza dos sexos, que constrói tal amor, mas a situação em que as mulheres se encontram. Como a mulher está "encerrada na esfera do relativo, destinada ao macho desde a infância, habituada a ver nele um soberano a quem não lhe é dado igualar-se" (Beauvoir, 1986b, p. 540), ela pensa o amor como uma submissão. Em segundo lugar, existe uma certa inautenticidade nesse amor-abdicação, independente das qualidades reais do homem amado: "ele não está à altura de justificar quem lhe rende um culto, e não se deixa possuir por ela" (Beauvoir, 1986b, p. 554). Para justificar sua abdicação, a mulher adorna o homem amado com qualidades quase divinas que justificam sua abdicação. A ambiguidade da submissão se revela no contraste entre as qualidades que o homem deveria ter para justificar a abdicação a seu favor, e a realidade das suas qualidades: como nenhum ser humano se iguala a um deus, toda mulher que se submete a um homem por amor se prepara para a decepção. Por que abandonar tudo por alguém que merece tão pouco? Essa inautenticidade condena à infelicidade não apenas a mulher apaixonada, mas o homem amado. Quando a mulher não encontra no homem a justificação que espera obter para sua existência, quando o homem não parecer conhecer suficientemente o sacrifício que ela fez por ele, "sua generosidade converte-se desde logo em exigência" (Beauvoir, 1986b, p. 556). Aí está o impasse inevitável da submissão amorosa: "Põe sua alegria em servi-lo: mas é preciso que ele reconheça esse serviço com gratidão; o dom torna-se exigência, segundo a dialética comum da dedicação" (Beauvoir, 1986b, 
p. 560). Ao se fazer escrava, a mulher toma a forma de poder sobre o homem, ela estima que seu sacrifício confira deveres ao homem. Por amor, ela se faz escrava e o acorrenta.

Beauvoir resume o caráter irremediavelmente negativo ao mesmo tempo que amplamente difundido do amor abdicação vivido pelas mulheres em uma referência a Andersen: "assumindo-se como o inessencial, aceitando uma dependência total, a mulher cria um inferno para si; toda amorosa se reconhece na pequena sereia de Andersen que, tendo, por amor, trocado sua cauda de peixe por pernas de mulher, andava sobre agulhas e carvões em brasa" (Beauvoir, 1986b, p. 554). O amor é, do ponto de vista dos homens, o que justifica a opressão das mulheres, e na visão das mulheres, é aquilo que organiza seu destino e sua experiência cotidiana enquanto as condena ao fracasso.

\section{O AMOR-INDEPENDÊNCIA COMO VIA PARA A EMANCIPAÇÃO}

Ao levar em conta a dimensão erótica do amor, Beauvoir pôde ir além de apenas constatar que o amor-abdicação faz com que as mulheres, ao se confrontarem com as normas sociais, se coloquem em uma situação insustentável e destinada ao fracasso. Consequentemente, enquanto a ambiguidade do amor como submissão conduziria a pensar no destino amoroso das mulheres como inelutavelmente negativo, a atenção à dimensão erótica desse amor permite três coisas: mostrar que o amor tradicional conduz, contra o que poderíamos pensar, a um fracasso erótico para os homens, que a ambiguidade do erotismo feminino tem um aspecto positivo e autêntico que necessita do amor para se manifestar e que, consequentemente, o erotismo convida a uma reformulação do amor segundo a qual o amor seja uma via de emancipação.

Para os homens, o amor tradicional permite escapar à agonia do reconhecimento mútuo. Ao mesmo tempo, esse amor tradicional é um obstáculo no nível erótico: ao construir a mulher como um Outro, o homem deseja nela o que há de estranho, estrangeiro e inatingível. Consequentemente, é inerente ao amor uma dialética implacável que faz a mulher-Outro ser sistematicamente inatingível para o homem. Primeiramente, segundo Beauvoir, está na própria natureza do desejo a busca por destruir seu objeto, consumindo- $0^{16}$. Mais especificamente, Beauvoir mostra que no amor tradicional, o uso sexual que o homem quer - e faz - da mulher

16 "Um dos fins a que visa todo desejo é a consumação do objeto desejado, o que implica sua destruição. Destruindo o hímen, o homem possui o corpo feminino mais intimamente do que mediante uma penetração que o deixa intato; com essa operação irreversível o homem faz dele um objeto inequivocamente passivo, afirma seu domínio sobre ele" (Beauvoir, 1986a, p.262). 
destrói as virtudes que fazem dela desejável: "O próprio uso que o homem faz dela destrói suas virtudes” (Beauvoir, 1986a, p. 269), ela não é mais virgem depois de ter sido possuída, ela não é mais reservada e castano enlace carnal.

Esse fracasso inerente ao erotismo masculino tradicional é uma fonte de opressão contínua sobre as mulheres, que se refazem como presas sem cessar, objetos para um desejo que em sua própria natureza está condenado a desaparecer $^{17}$. Mas é igualmente fonte de sofrimento para o próprio homem. Na sua crítica à ideia de mistério feminino - que é uma outra manifestação de uma qualidade desejável aos olhos do homem e que desaparece de forma decepcionante uma vez que o amor é consumado -, Beauvoir demonstra que através desse amor que vê a mulher como mítica e irreal, o homem não consegue realmente encontrar a mulher que ele ama. Ele acaba ficando só com seu amor ao invés de obter, graças a tal amor, uma relação autêntica com um ser humano ${ }^{18}$.

Assim, à existência dispersa, contingente e múltipla das mulheres, o pensamento mítico opõe o Eterno Feminino único e cristalizado; se a definição que se dá desse Eterno Feminino é contrariada pela conduta das mulheres de carne e osso, estas é que estão erradas. Declara-se que as mulheres não são femininas e não que a Feminilidade é uma entidade. Os desmentidos da experiência nada podem contra o mito. Entretanto, de certa maneira, este tem sua fonte nela. Assim é exato que a mulher é outra e essa alteridade é concretamente sentida no desejo, no carinho, no amor; mas a relação real é de reciprocidade; como tal, ela engendra dramas autênticos: através do erotismo, do amor, da amizade e suas alternativas de decepção, ódio, rivalidade, ela é luta de consciências que se consideram essenciais, é reconhecimento de liberdades que se confirmam mutuamente, é a passagem indefinida da inimizade à cumplicidade. Pôr a Mulher é pôr o Outro absoluto, sem reciprocidade, recusando contra a experiência que ela seja um sujeito, um semelhante. (Beauvoir, 1986a, p. 395)

17 "É preciso inventar novas seduções para o amante, é preciso tornar-se a mulher que ele almeja encontrar e possuir. Mas todo esforço é vão; ela não ressuscitará em si essa imagem da Outra que de início o atraíra, que pode atraí-lo em uma outra. Há no amante a mesma dúplice e impossível exigência que há no marido: quer a amante absolutamente sua e, no entanto, estranha; ele a quer exatamente de acordo com seu sonho e diferente de tudo o que sua imaginação inventa, uma resposta à sua espera e uma surpresa imprevista. Essa contradição atormenta a mulher e a destina ao fracasso" (Beauvoir, 1986b, p. 568).

18 "Graças ao mistério, perpetua-se essa relação negativa que se afigurava a Kierkegaard infinitamente preferível a uma posse positiva; diante de um enigma vivo, o homem permanece só: só com seus sonhos, esperanças, temores, amor e vaidade; esse jogo subjetivo que pode ir do vício ao êxtase místico é para muitos uma experiência mais atraente do que uma relação autêntica com um ser humano" (Beauvoir, 1986a, p. 399). 
Se Beauvoir manifesta o que é contraditório em uma existência autêntica, na concepção tradicional de amor, ela não abandona o amor em nome, por exemplo, da amizade - como fazem crer certas ideias preconcebidas sobre ela. Ao contrário, ela afirma que o amor é necessário ao erotismo feminino e que consequentemente uma nova forma de amor, não opressiva, é necessária à mulher independente que se concebe, com razão, como ser de carne e osso.

Como afirma Sara Heinämaa (2006), Beauvoir propõe, n’OSegundo Sexo, um estudo do erotismo feminino, que se caracteriza pela sua ambiguidade. O erotismo qualificado como feminino funciona por ondas que estouram e se renovam, e tem uma fragilidade que o erotismo masculino não possui (Beauvoir, 1986a, p.155). É de sua natureza ser frágil e difícil de se sustentar. Mas é, ao mesmo tempo e fundamentalmente, mais autêntico. Beauvoir escreve, ao final do capítulo sobre iniciação sexual:

A experiência erótica é uma das que revelam aos seres humanos, da maneira mais pungente, a ambiguidade de sua condição; nela eles se sentem como carne e como espírito, como o outro e como sujeito. É para a mulher que esse conflito assume o caráter mais dramático, porque ela se apreende inicialmente como objeto, porque ela não encontra de imediato uma autonomia segura no prazer; ela precisa reconquistar sua dignidade de sujeito transcendente e livre, assumindo sua condição carnal: é um empreendimento difícil e cheio de riscos, no qual fracassa frequentemente. Mas a própria dificuldade da situação defende-a contra as mistificações em que o homem se deixa envolver; ele é amiúde enganado pelos privilégios falaciosos que implicam seu papel agressivo e a solidão satisfeita do orgasmo; ele hesita em se reconhecer plenamente como carne. A mulher tem de si mesma uma experiência mais autêntica. (Beauvoir, 1986b, p. 1880)

Esse erotismo ambíguo faz do amor uma necessidade e, ao mesmo tempo, faz do amor tradicional sistematicamente decepcionante, e até opressivo. Beauvoir mostra que a "natureza singular do erotismo feminino" (Beauvoir, 1986b, p. 596) faz com que esse erotismo sofra para se manifestar fora de um contexto amoroso, ou pelo menos em um contexto favorável. Segundo Beauvoir, a fragilidade do erotismo feminino se deve ao fato de ele passar por um prazer preso à objetificação na qual a mulher é feita de objeto pelo parceiro, antes de se transformar por uma captura indireta de si nesse ser-objeto. No entanto, o curso deste processo pode ser interrompido - e normalmente, o é - pelo desejo de possessão que se manifesta no desejo masculino: "tensão e atividade se harmonizam com seu erotismo, ao passo 
que a mulher, recusando a passividade, destrói o feitiço que a conduz ao prazer" (Beauvoir, 1986b, p. 601). O problema agora é saber como viver esse erotismo sem colocá-lo em risco pela diferença entre o erotismo masculino e conquistador, que encontra satisfação imediata, e o erotismo feminino ambíguo e frágil ${ }^{19}$. A mulher, segundo Beauvoir, deseja o reconhecimento mútuo que garante o amor e não se sentir humilhada nem pela sua própria passividade nem pela conquista sexual que faz dela objeto.

A diferença que a análise de Beauvoir prevê entre o erotismo masculino e o feminino leva a uma posição complexa: de um lado, ela mostra que a maneira pela qual as normas sociais constroem o amor, no sentido tradicional, leva ao fracasso do erotismo masculino, o qual sempre prescinde de seu objeto, e do erotismo feminino, que nunca se desenvolve plenamente em sua complexidade, fragilidade e autenticidade. Mas de outro lado, a tese que o erotismo feminino é mais complexo e profundo do que o erotismo masculino por se manifestar autenticamente, e por ser o amor do homem pela mulher necessário para essa manifestação, leva Beauvoir a defender uma filosofia do amor como caminho para a liberdade e para a emancipação feminina.

Para Beauvoir, a atenção ao erotismo é um convite à construção de uma nova forma de amor, um amor emancipatório, que recusa os mitos da feminilidade e da masculinidade, em favor de um amor pelo outro em sua realidade, que passe por um reconhecimento mútuo, mas que difira da simples amizade por se construir em uma "reciprocidade carnal". Ela defende a possibilidade de um amor que, similar à amizade que aparece no início da seção dedicada aos mitos no primeiro volume, permita o respeito da humanidade do outro sem reduzi-lo a um mito. A tese subjacente e decisiva de Beauvoir sobre o amor é que o mito não só lhe é dispensável como também o danifica:

recusar os mitos não é destruir toda relação dramática entre os sexos, não é negar as significações que se revela autenticamente ao homem através da realidade feminina; não é suprimir a poesia, o amor, a aventura, a felicidade, o sonho: é

19 É importante notar aqui que Beauvoir não concebe nenhum desses erotismos como manifestações naturais da diferença entre os sexos. Os capítulos sobre a formação das mulheres que abrem o segundo volume d'O Segundo Sexo mostram detalhadamente como o erotismo da jovem mulher é produzido pela organização patriarcal da sociedade. Beauvoir escreve: "a sexualidade, de resto, nunca apareceu para nós como definindo um destino, como fornecendo em si a chave das condutas humanas, mas sim como exprimindo a totalidade de uma situação que contribui para definir" (Beauvoir, 1986b, p. 634). 
somente pedir que as condutas, os sentimentos, as paixões assentem na verdade. (Beauvoir, 1986b, p. 406)

se aceitassem amar uma semelhante, de preferência a uma escrava - como o fazem aliás os que, entre eles, são isentos de arrogância e de complexo de inferioridade - as mulheres seriam muito menos obcecadas pela sua feminilidade; ganhariam com isso naturalidade, simplicidade, e se achariam mulheres sem tanto esforço, pois, afinal de contas, o são. (Beauvoir, 1986b, p. 592)

Renunciar os mitos não leva a uma renúncia do amor, mas daquilo que é opressivo, inautêntico e até mesmo mortal no amor: não se trata, portanto, de renunciar o amor, mas renunciar a utilização do amor para fixar os seres em identidades míticas que os impedem de alcançar sua liberdade.

Esse amor emancipatório é um amor autêntico por procurar uma "relação entre-humana" (Beauvoir, 1986b, p. 554) e, sobretudo, por permitir, ao invés de evitar, o reconhecimento mútuo das liberdades como na amizade:

O amor autêntico deveria basear-se no reconhecimento recíproco de duas liberdades; cada um dos amantes se sentiria então como si mesmo e como o outro: nenhum abdicaria sua transcendência, nenhum se mutilaria; ambos desvendariam juntos, no mundo, valores e fins. Para um e para outro, o amor seria uma revelação de si mesmo pelo dom de si e o enriquecimento do universo. (Beauvoir, 1986b, p. 571)

O amor ocupa um lugar similar à amizade, mas sua autenticidade é reforçada e possibilitada por sua dimensão erótica. Reconhecer a humanidade do outro impede o amor tradicional - que fixa as identidades e instaura a opressão das mulheres - e limita o desejo em suas tendências imperativas e totalizantes - ao se reconhecer a liberdade do outro, não se deseja consumi-lo completamente. Ao mesmo tempo, a condição carnal e desejante dos seres humanos necessita uma reinvenção do amor para que o erotismo possa ser vivido em sua ambiguidade, a qual the confere uma qualidade excepcional. $\mathrm{O}$ amor-liberdade se vive como uma "reciprocidade carnal" que clama por liberdade. De certa maneira, é o "calor vivo do desejo", a experiência humana em sua dimensão carnal, que abre o caminho para a invenção de um amor-independência, primeiro passo em direção à emancipação das mulheres, e dos homens junto delas. 


\section{CONCLUSÃO}

Eu defendi aqui que o amor é central para a análise que Simone de Beauvoir faz da opressão das mulheres na medida em que constitui o fundamento ideológico da objetificação das mulheres e estrutura as ambiguidades das experiências vividas da opressão. Mas ele constitui um elemento decisivo da ambição normativa e emancipatória d'O Segundo Sexo, uma vez que o amor romântico, em sua dimensão erótica, é o que abre no nível individual a possibilidade de uma parceria igualitária, autêntica e livre entre homens e mulheres. Isso não quer dizer, entretanto, que devamos ler essa filosofia do amor como uma certeza de que a emancipação se produzirá pelo nível individual: a conclusão d'O Segundo Sexo deixa claro que o amor-liberdade só pode emergir de um contexto de transformação estrutural da sociedade. Como escreveu Beauvoir nas últimas páginas d’O Segundo Sexo, "para que uma mulher pudesse ser amorosa à maneira de um homem, isto é, sem pôr em causa seu próprio ser, em liberdade, seria preciso que se pensasse sua igual, que o fosse concretamente. Seria preciso que se empenhasse com a mesma decisão em seus empreendimentos, o que, como vamos ver, não é ainda frequente" (Beauvoir, 1986b, p. 607). Sem liberdade concreta, o erotismo feminino se vê bloqueado pelo amor tradicional, sem possibilidade de se superar em um amor que seja ao mesmo tempo emancipatório, carnal e amistoso.

\section{REFERÊNCIAS}

BAUER, Nancy (2001a). Being with as Being-against: Heidegger meets Hegel in The Second Sex. Continental Philosophy Review, vol. 34 .

BAUER, Nancy (2001b). Simone de Beauvoir, Philosophy, and Feminism. New York City: Columbia University Press.

BEAUVOIR, Simone de (1983). Lettres à Sartre, Paris: Gallimard.

BEAUVOIR, Simone de (1986a). Le deuxième sexe, vol. I. Collection Folio essais. Paris: Gallimard.

BEAUVOIR, Simone de (1986b).Le deuxième sexe, vol. II. Collection Folio essais. Paris: Gallimard.

BEAUVOIR, Simone de (1997). Lettres à Nelson Algren. Un amour transatlantique (19471964). Paris: Gallimard.

BEAUVOIR, Simone de (2008). Cahiers de Jeunesse (1926-1930). Paris: Gallimard. BEAUVOIR, Simone de (1960).La Force de l'âge.Paris, Gallimard.

BEAUVOIR, Simone de; BOST, Jacques-Laurent (2004). Correspondance croisée. Paris: Gallimard. 
CLEARY, Skye (2017).“Simone de Beauvoir on Love”. In: GRAU, Christopher e SMUTS, Aaron (org).The Oxford Handbook of Philosophy of Love. Oxford: Oxford University Press.

HEINÄMAA, Sara (2006). “Through Desire and Love': Simone de Beauvoir on the Possibilities of Sexual Desire”. In: MORTENSEN, Ellen. Sex, Breath, and Force. Sexual Difference in a Post-Feminist Era. Oxford: Lexington Books.

KIRKPATRICK, Kate (2019). Becoming Beauvoir: A Life. London: Bloomsbury.

KLAW, Barbara (1997). Desire, Ambiguity, and Contingent Love: Simone de Beauvoir, Sexuality, and Self-Creation, or What Good is Man Anyway?. Symposium: A Quarterly Journal in Modern Literatures, Vol. 51, $\mathrm{N}^{\mathrm{O}} 2$.

LACAZE, Marguerite (2015). "The Time of Possible and Impossible Reciprocity: Love and Hate in Simone de Beauvoir”. In: ENNS, Diane; CALCAGNO, Antonio (org.). Thinking About Love: Essays in Contemporary Continental Philosophy. University Park: Pennsylvania State University Press.

LAMBLIN, Bianca (1993). Mémoires d'unejeune fille dérangée. Paris: Balland.

LUNDGREN-GOTHLIN, Eva (1991). Sexe et Existence. La philosophie de Simone de Beauvoir. Paris: Éditions Michalon.

MCMULLIN, Irene (2011). Love and Entitlement: Sartre and Beauvoir on the Nature of Jealousy. Hypatia, Vol. 26, $\mathrm{N}^{\circ} 1$.

PETTERSEN, Tove (2017). "Love According to Simone de Beauvoir" in HENGEHOLD, Laura; BAUER, Nancy (org.). A Companion to Simone de Beauvoir. Oxford: Wiley and Sons.

Recebido: 19/08/2021 | Aprovado: 14/09/2021 